\title{
Interactions among two strains of Tubifex tubifex (Oligochaeta: Tubificidae) and Myxobolus cerebralis (Myxozoa)
}

\author{
Leah C. Steinbach Elwell ${ }^{1}$, Billie L. $\operatorname{Kerans}^{1, *}$, Charlotte Rasmussen ${ }^{1,2}$, \\ James R. Winton ${ }^{2}$
}

${ }^{1}$ Montana State University, Department of Ecology, 310 Lewis Hall, Bozeman, Montana 59717, USA

${ }^{2}$ Western Fisheries Research Center, USGS, 6505 NE 65th Street, Seattle, Washington 98115, USA

\begin{abstract}
Host-parasite interactions influence host population growth, host evolution and parasite success. We examined the interactions among Myxobolus cerebralis, the parasite that causes salmonid whirling disease, and resistant and susceptible strains of the oligochaete host Tubifex tubifex. Strains of T. tubifex with diverse genotypes often coexist in nature and have variable susceptibilities to $M$. cerebralis infection. Further, parasite proliferation differs by several orders of magnitude among $T$. tubifex strains. We examined total biomass produced by individual $T$. tubifex, including progeny production and adult growth, parasite proliferation and prevalence of infection using 2 strains of $T$. tubifex at 2 myxospore doses in a response-surface experimental design. Total biomass production per individual oligochaete and progeny biomass produced by an individual adult oligochaete were density-dependent for both resistant and susceptible individuals and the effects did not change with the addition of myxospores. However, both resistant and susceptible adults had highest growth when exposed to $M$. cerebralis. The presence of resistant oligochaetes in mixed cultures did not reduce the infection prevalence or parasite proliferation in susceptible individuals. In natural aquatic communities, resistant strains of $T$. tubifex may not reduce the effects of $M$. cerebralis on the salmonid host, particularly if sufficient numbers of susceptible T. tubifex are present.
\end{abstract}

KEY WORDS: Parasite-mediated competition · Tubifex tubifex $\cdot$ Myxobolus cerebralis $\cdot$ Genetic variation $\cdot$ Whirling disease $\cdot$ Host susceptibility

\section{INTRODUCTION}

Parasite-mediated competition among hosts was first noted in Park's (1948) classical experiment showing that a protozoan parasite could reverse the outcome of competition between 2 Tribolium beetle species. Later research focused on the importance of parasite-mediated interactions among competing species (e.g. Price et al. 1988, Settle \& Wilson 1990, Grosholz 1992, Schall 1992, Yan et al. 1998). However, interactions among genetic strains of the same host species may also be mediated by parasites, which can have differential effects on strains (Subbarao et al. 1988). Models of parasite-mediated competition predict that in the pres- ence of a parasite, hosts with low susceptibility will be superior competitors to hosts with high susceptibility (Yan 1996). Ultimately, these differences in host-parasite dynamics can determine the outcome of interactions among hosts and the success of parasites (Ebert et al. 1998, Yan et al. 1998).

We examined variation within and between strains of Tubifex tubifex in response to parasitism by Myxobolus cerebralis (Myxozoa: Myxosporea/Actinosporea), the causative agent of whirling disease in salmonids (El-Matbouli et al. 1992). The parasite alternates between 2 obligate hosts: various salmonid species and 1 aquatic oligochaete species, T. tubifex (Oligochaeta: Tubificidae) (Markiw \& Wolf 1983, Wolf 
\& Markiw 1984). M. cerebralis has 2 spore stages, the myxospore and the triactinomyxon (TAM), that are produced within salmonids and $T$. tubifex, respectively.

Tubifex tubifex is a widespread and environmentally tolerant oligochaete that is found in most aquatic habitats (Brinkhurst \& Jamison 1971, Chapman et al. 1982). The success of $T$. tubifex may result from its genetic diversity. There are several genetically distinct lineages among T. tubifex populations from various locations in North America and Europe (Anlauf 1994, 1997, Sturmbauer et al. 1999, Erséus et al. 2000, Beauchamp et al. 2001, 2002, Kerans et al. 2004), and local populations of $T$. tubifex may consist of multiple strains (Beauchamp et al. 2002, Granath \& Gilbert 2002). Strains of $T$. tubifex can differ in their reproduction, growth rates, environmental preferences and susceptibility to Myxobolus cerebralis (Poddubnaya 1980, Milbrink 1983, Stevens et al. 2001, Kerans et al. 2004).

The effects of Myxobolus cerebralis on Tubifex tubifex depend on the susceptibility of the strain of T. tubifex. M. cerebralis may cause increased mortality and decreased reproductive output of $T$. tubifex strains; the strengths of these effects are related to the number of TAMs released (Stevens et al. 2001, Kerans et al. 2004). When challenged with similar doses of myxospores, highly susceptible strains of $T$. tubifex released large numbers of TAMs with considerable impairment to T. tubifex population growth, whereas strains with lower susceptibility produced fewer TAMs and their success was not as impaired (Kerans et al. 2004). Because individual T. tubifex compete for resources and their growth and reproduction are density-dependent (Kosiorek 1974, Bonacina et al. 1989), the presence of the parasite may alter the genetic structure of $T$. tubifex populations by decreasing the relative abundance of susceptible strains.

The effects of Tubifex tubifex on Myxobolus cerebralis also depend on the susceptibility of the strain of T. tubifex. Some laboratory strains of $T$. tubifex resist infection and do not release TAMs (Beauchamp et al. 2002). Resistant T. tubifex may be immune to myxospore invasion or capable of deactivating myxospores prior to invasion (El-Matbouli et al. 1999a, Beauchamp et al. 2002). If resistant T. tubifex deactivate myxospores, then the presence of a significant number of resistant $T$. tubifex in a mixed population might reduce infection levels among susceptible individuals. Plausibly, T. tubifex populations comprising of multiple genetic strains that vary in susceptibility could influence the transmission success of $M$. cerebralis and result in variable infection pressure on salmonids.

We conducted a laboratory experiment that examined interactions among susceptible and resistant
Tubifex tubifex and Myxobolus cerebralis. The major objectives of this research were to determine: (1) whether the interactions between strains of T. tubifex differed in strength or direction when they were exposed and not exposed to $M$. cerebralis; (2) whether resistant $T$. tubifex influenced the transmission of $M$. cerebralis by susceptible T. tubifex; and (3) whether resistant $T$. tubifex can be infected when exposed to high doses of myxospores.

\section{MATERIALS AND METHODS}

Strains of oligochaetes and origin of parasite. Wused 2 strains of Tubifex tubifex from disease-free laboratory cultures: the Mt. Whitney strain has released large numbers of TAMs in previous experiments (Stevens et al. 2001, Kerans et al. 2004), and the Great Lakes strain was reported resistant to Myxobolus cerebralis infection (Beauchamp et al. 2002). The Mt. Whitney strain was collected from the settling ponds at the California Mt. Whitney Hatchery, USA, where $M$. cerebralis has been endemic since 1984 (Modin 1998). The Great Lakes strain was obtained from sediments in Lakes Erie and Ontario (Reynoldson et al. 1996), where $M$. cerebralis was first documented in the 1950s in wild salmonids (R. Nelson, United States Fish and Wildlife Service, La Crosse, Wisconsin, pers. comm.). The strains have been genetically characterized and maintained in the laboratory (see Stevens et al. 2001, and Kerans et al. 2004 for detailed culture propagation methods).

Myxobolus cerebralis myxospores were extracted from infected rainbow trout Oncorhynchus mykiss using the continuous plankton centrifuge method (O'Grodnick 1975). Trout were obtained from the Montana Ennis Hatchery, USA, and were infected in our laboratory with TAMs produced by the United States Fish and Wildlife Service, Fish Health Laboratory, Bozeman, Montana. The abundance of myxospores was determined by counting all viable myxospores in $1 \mu \mathrm{l}$ of myxospore suspension on a hemacytometer with a compound microscope (40× magnification). The total number of myxospores in the suspension was extrapolated from the mean number of myxospores from 4 hemacytometer counts. The suspension was evenly mixed on a magnetic stirrer as experimental doses of myxospores were removed and administered to oligochaetes.

Laboratory trials. The laboratory experiment examined the intra-strain and inter-strain interactions between Mt. Whitney and Great Lakes Tubifex tubifex when myxospores were present and absent. Sets of cultures containing $50 \mathrm{Mt}$. Whitney T. tubifex, 100 Mt. Whitney T. tubifex, $50 \mathrm{Mt}$. Whitney T. tubifex + 
50 Great Lakes T. tubifex, 50 Great Lakes T. tubifex and 100 Great Lakes T. tubifex were exposed to 0 (3 replicates) or 2500 (4 replicates) myxospores per container $(9 \times 9 \times 5 \mathrm{~cm})$, in a response-surface competition design (Goldberg \& Scheiner 2001). The densities of 50 and 100 oligochaetes in these containers corresponded to oligochaete densities of 6180 and 12360 ind. $\mathrm{m}^{-2}$, respectively, a density range that is commonly found in rivers (Lazim \& Learner 1986). Oligochaetes were exposed to myxospores for $5 \mathrm{~d}$. This combination of myxospore dose and exposure time was chosen because it had produced infection rates below $100 \%$ in previous experiments (Steinbach 2003). Consequently, interactions between $T$. tubifex strains could be examined at an abundance of myxospores that caused infection but did not obscure effects of the interactions. Additionally, 1 treatment with 3 replicates each containing 100 Great Lakes T. tubifex were exposed to 50000 myxospores for $5 \mathrm{~d}$ in an effort to infect this strain.

The Tubifex tubifex strains were removed from mass cultures, placed in plastic containers for $24 \mathrm{~h}$ without substrate to equalize hunger levels, and then wetweighed in groups of 50 to the nearest $0.0001 \mathrm{~g}$. The appropriate numbers of oligochaetes were placed in plastic containers with $40 \mathrm{ml}$ of sand, $1 \mathrm{ml}$ of organic matter, and $200 \mathrm{ml}$ of dechlorinated tap water and the myxospore suspension was added. A similar quantity of suspension from parasite-free rainbow trout was added to treatments without myxospores. After $5 \mathrm{~d}$, all oligochaetes were removed from their original container and placed in a new container with fresh substrate and water. Containers were maintained in incubators at $15^{\circ} \mathrm{C}$ with a $12: 12 \mathrm{~h}$ light:dark photoperiod and supplied with a constant flow of air. In each container, oligochaetes were fed 0.10 to $0.12 \mathrm{~g}$ of dried Spirulina sp. and had about $95 \%$ of the water replaced with fresh dechlorinated water weekly.

Assays for infection. Scanning for TAMs began on Day 65 post-exposure to myxospores and prior to expected TAM release (El-Matbouli \& Hoffmann 1989, El-Matbouli et al. 1999b, Stevens et al. 2001, Kerans et al. 2004). The water from each container was poured separately through a $20 \mu \mathrm{m}$ sieve that retained TAMs, which were then diluted to $10 \mathrm{ml}$ with water. Two $55 \mu \mathrm{l}$ aliquots were scanned using a phase-contrast microscope (100× magnification) every $3 \mathrm{~d}$ until TAMs were found. After TAMs were detected, they were counted weekly until Day 108 post-exposure. After Day 108 post-exposure, 2 of the myxospore-exposed replicates were used to assess prevalence of infection (see below); however, TAMs from the 2 remaining myxospore-exposed replicates were counted until the experiment was terminated on Day 135 post-exposure. Until termination of the experiment, we also scanned 3 replicates of each treatment that were not exposed to myxospores to confirm the absence of TAMs.

The average number of TAMs released by each replicate for each week was extrapolated from the mean number of TAMs counted from 2 slides. Total TAMs released by a replicate was calculated by summing the average number of TAMs released by each replicate each week. For comparison, we calculated TAMs released $\mathrm{d}^{-1}$ by dividing the total TAMs released by a replicate by the number of days observed because the total number of days that TAMs were counted differed among treatments (i.e. 108 or 135). In addition, TAMs released ind. ${ }^{-1} \mathrm{~d}^{-1}$ was calculated by dividing the total TAMs released by the number of individuals releasing TAMs and the number of days observed.

On Day 108 post-exposure, 2 replicates from each myxospore treatment were randomly chosen to determine the prevalence of infection. By Day 108 postexposure, we assumed that most oligochaetes that were infected would be releasing TAMs. Adult oligochaetes were placed individually in 12-well plates (4 ml capacity). After $2 \mathrm{~d}$ to allow TAMs to accumulate in the wells, plates were scanned twice within a $10 \mathrm{~d}$ period with a dissecting microscope $(40 \times$ magnification) and individuals were recorded as infected if TAMs were visible in the well. The prevalence of infected Tubifex tubifex was calculated for each replicate by dividing the number of individuals releasing TAMs by the total number of T. tubifex observed times 100. TAM response variables from the $50 \mathrm{Mt}$. Whitney + 50 Great Lakes T. tubifex treatments were calculated with 50 oligochaetes because the genetic assay showed that only Mt. Whitney $T$. tubifex released TAMs (see 'Results').

At the termination of a replicate (either Day 108 or Day 135 post-exposure), all adults and progeny were weighed to the nearest $0.0001 \mathrm{~g}$. Further, because strains of Tubifex tubifex are morphologically identical, all adults from 50 Mt. Whitney T. tubifex +50 Great Lakes $T$. tubifex treatments were analyzed with molecular markers to identify the strain of each individual (see 'Genetic analyses' below). At least 30 randomly chosen progeny from each replicate were also analyzed using molecular markers to determine the abundance of the progeny of each strain.

We measured 3 responses to assess the effects of interactions among strains of Tubifex tubifex and Myxobolus cerebralis on the fitness of the oligochaetes: (1) total biomass production ind. ${ }^{-1} \mathrm{~d}^{-1}$ ([final adult weight-initial adult weight] + [final progeny weight]/initial density of adults · days of growth) (hereafter referred to as 'total biomass'); (2) adult growth initial ind. ${ }^{-1} \mathrm{~d}^{-1}$ ([(final adult weight/final density) - (initial adult weight/initial density of 
adults)]/days of growth) (hereafter referred to as 'adult growth'); and (3) progeny biomass produced by an individual adult $\mathrm{d}^{-1}$ (final progeny weight/initial density of adults - days of growth) (hereafter referred to as 'progeny biomass'). Thus, total biomass was separated into adult growth and progeny biomass to determine how each was affected by other strains and the parasite. Oligochaete mortality was not examined as a response variable because it was low during this experiment $(1.74 \%$ mortality $\pm 1 \% \mathrm{SE}, \mathrm{n}=35)$.

Genetic analyses. To identify the strain of each Tubifex tubifex within the treatments containing 50 Mt. Whitney +50 Great Lakes T. tubifex, a maximum of 3 randomly amplified polymorphic DNA (RAPD) primers were used that provided distinctive banding differences between the strains. Genomic DNA was extracted from whole adult and progeny $T$. tubifex using Nucleospin ${ }^{\circledR}$ Multi-96 tissue kits as per BD Biosciences Clontech protocol (PT3629-1), and was frozen until needed. The quantity and quality of DNA was assessed using gel electrophoresis with $5.0 \mu \mathrm{l}$ of sample DNA on $1.5 \%$ agarose gels with $0.5 \times$ Tris-acetate (TAE) buffer. Ethidium bromide was used to visualize the DNA bands and all gels were documented using Lab Works ${ }^{\circledR}$ program with a UVP EPI-Chemi dark room.

Only 1 RAPD primer (5'-GGG CCG TTT A-3') was necessary to determine the strain of adult Tubifex tubifex using polymerase chain reaction (PCR)-amplified DNA. The PCR reaction mixture and conditions were as described in Kerans et al. (2004), with the exception of an annealing temperature of $46^{\circ} \mathrm{C}$. Following PCR amplification, products were visualized by electrophoresis on $2 \% 0.5 \times$ TAE agarose gels.

Individual oligochaetes from treatments containing 50 Mt. Whitney + 50 Great Lakes Tubifex tubifex were allocated to a strain by different banding patterns from PCR products and the proportion of each strain was calculated by dividing the number of each strain identified by PCR by the total number of T. tubifex identified. The proportion of each strain could then be applied to biomass calculations. To determine the strain of each progeny, we analyzed individual progeny using 3 RAPD primers (No. 18: 5'-GGG CCG TTT A-3', No. 2: 5'-CCT GGG CTT G-3', and No. 54: 5'GTC CCA GAG C-3'). We used 3 primers to reduce the possibility of not recognizing a hybrid progeny. Considering the number of banding pattern differences (at least 2 between each strain among each primer), we had a 1 in $8(1 / 2 \times 1 / 2 \times 1 / 2)$ chance of not recognizing a progeny that was a hybrid. The relative proportion of each strain was calculated by dividing the identified strain number by the total number of progeny amplified which was then applied to calculate the total number of progeny produced per strain.
Statistical analyses. Initially, TAMs released $\mathrm{d}^{-1}$, TAMs released ind. ${ }^{-1} \mathrm{~d}^{-1}$ and all biomass variables were tested for differences between the 2 ending dates for the experiment (final observation = Day 108 or Day 135) using 2-factor analyses of variance (ANOVAs), (SAS Institute 2001). These variables did not differ between days, oligochaete strain-density combinations (hereafter referred to as oligochaete combinations), or with the interaction between the 2 factors (all p-values $>0.46$ ). Therefore, all replicates, regardless of end date, were combined for further analyses.

Each biomass variable was tested for significant differences among oligochaete combinations and myxospore doses using 2-factor ANOVAs (SAS Institute 2001). Residuals were examined for normality and variances were stabilized with $\ln$ transformations where necessary. The treatment of 100 Great Lakes Tubifex tubifex with 50000 myxospores was not used in these analyses because its inclusion made the ANOVA unbalanced. Instead, we compared total biomass, adult growth and progeny biomass between the treatments of 100 Great Lakes T. tubifex that were exposed and not exposed to 50000 myxospores using Student's $t$-tests (SAS Institute 2001).

Total TAMs released $\mathrm{d}^{-1}$, TAMs released ind. ${ }^{-1} \mathrm{~d}^{-1}$ and prevalence of infected Tubifex tubifex were tested for significant differences among oligochaete combinations using 1-way ANOVAs (SAS Institute 2001). The response variables were examined for normality and homogeneity of variance and did not require transformation. Tukey's honestly significant differences tests (Tukey's HSD) were used in all analyses to determine differences among treatment levels when main effects were significant $(p<0.05)$.

\section{RESULTS}

The total biomass produced by each strain was highest in groups containing 50 individuals alone and decreased as the number of oligochaetes increased to 100 with the addition of either strain of Tubifex tubifex (Fig. 1, Table 1, Tukey's HSD, $\mathrm{p}<0.05)$. Total biomass did not differ between T. tubifex exposed (mean $\pm 1 \mathrm{SE}$ : $0.25 \pm$ $0.03 \mathrm{mg}$ ind..$\left.^{-1} \mathrm{~d}^{-1}\right)$ and not exposed $(0.26 \pm 0.02 \mathrm{mg}$ ind. ${ }^{-1} \mathrm{~d}^{-1}$ ) to myxospores (Table 1$)$. The interaction between oligochaete combination and myxospore dose was not significant (Table 1).

The progeny biomass produced by an individual adult was greatest in groups containing 50 individuals alone. When abundances increased to 100 with the addition of either strain, the progeny biomass decreased (Fig. 1, Table 1, Tukey's HSD, p < 0.05). Progeny biomass did not differ between 0 (mean \pm 1 SE: $0.24 \pm$ $0.02 \mathrm{mg}$ ind.$\left.^{-1} \mathrm{~d}^{-1}\right)$ or 2500 myxospore treatments $(0.21$ 


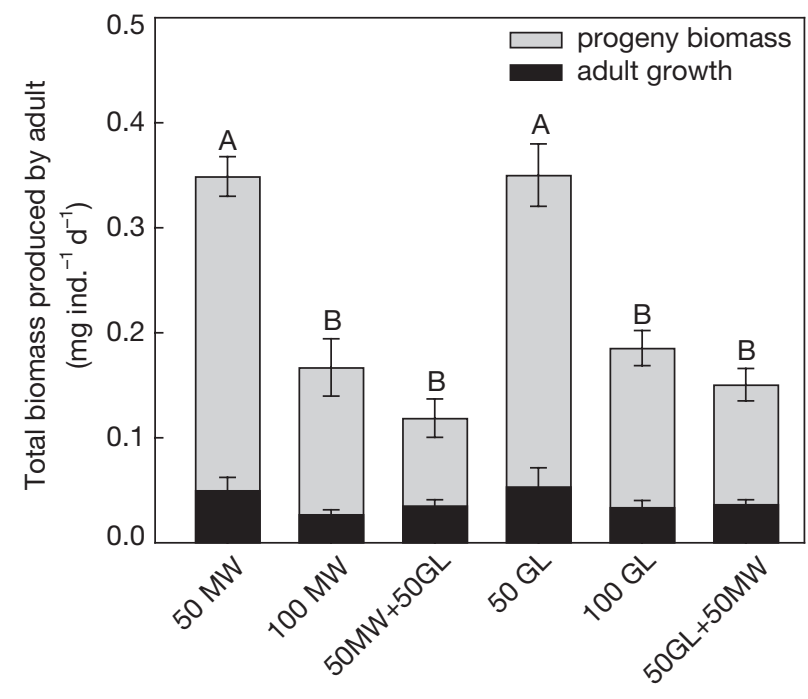

Fig. 1. Tubifex tubifex adult growth and progeny biomass of individual Mt. Whitney (MW) and Great Lakes (GL) individuals. The height of each bar represents total biomass (mg ind. ${ }^{-1}$ $\mathrm{d}^{-1}$ ). Total biomass is divided into progeny biomass and adult growth. Letters indicate significantly different progeny biomass and total biomass among oligochaete combinations; there were no significant differences among oligochaete com-

binations for adult growth. Error bars $=1 \mathrm{SE}$ of mean

$\pm 0.024 \mathrm{mg}$ ind $^{-1} \mathrm{~d}^{-1}$ ) (Table 1). The interaction between oligochaete combination and myxospore dose was not significant (Table 1).

The growth of individual adults did not differ among oligochaete combinations (Fig. 1, Table 1,

Table 1. Tubifex tubifex exposed to Myxobolus cerebralis. Analysis of variance of the effects of oligochaete combination and myxospore dose on biomass response-variables. Only adult growth required transformation (In). All variables are expressed as a per capita daily rate. Statistically significant effects $(p<0.05)$ are in bold. SS: sum of squares

\begin{tabular}{|lcccc|}
\hline $\begin{array}{l}\text { Response variable } \\
\text { Source }\end{array}$ & SS & $F$ & df & $\mathrm{p}$ \\
\hline Total biomass & & & & \\
Dose & 0.001 & 0.34 & 1 & 0.566 \\
Oligochaete combination & $\mathbf{0 . 4 1 3}$ & $\mathbf{2 5 . 1 5}$ & $\mathbf{5}$ & $<\mathbf{0 . 0 0 0 1}$ \\
Interaction & 0.021 & 1.28 & 5 & 0.298 \\
Error & 0.098 & & 30 & \\
Adult growth & & & & \\
Dose & $\mathbf{2 . 0 0 E - 0 4}$ & $\mathbf{9 . 9 0}$ & $\mathbf{1}$ & $\mathbf{0 . 0 0 3}$ \\
Oligochaete combination & $9.00 \mathrm{E}-05$ & 0.92 & 5 & 0.483 \\
Interaction & $3.00 \mathrm{E}-05$ & 0.30 & 5 & 0.912 \\
Error & $6.00 \mathrm{E}-04$ & & 30 & \\
Progeny biomass & & & & \\
Dose & 0.010 & 3.13 & 1 & 0.087 \\
Oligochaete combination & $\mathbf{0 . 3 4 2}$ & $\mathbf{2 1 . 8 8}$ & $\mathbf{5}$ & $<\mathbf{0 . 0 0 0 1}$ \\
Interaction & 0.015 & 0.95 & 5 & 0.466 \\
Error & 0.094 & & 30 & \\
\hline
\end{tabular}

Tukey's HSD, p < 0.05). Growth of adults was greater in the groups exposed to 2500 myxospores (mean \pm $1 \mathrm{SE}: 0.013 \pm 0.001 \mathrm{mg}$ ind. ${ }^{-1} \mathrm{~d}^{-1}$ ) than in the groups not exposed to myxospores $\left(0.009 \pm 0.0005 \mathrm{mg}\right.$ ind $^{-1}$ $\mathrm{d}^{-1}$ ) (Table 1). The interaction between oligochaete combination and myxospore dose was not significant (Table 1).

The total biomass of Great Lakes Tubifex tubifex was greater when exposed to 0 myxospores (mean \pm $1 \mathrm{SE}: 0.2316 \pm 0.015 \mathrm{mg}$ ind.$^{-1} \mathrm{~d}^{-1}$ ) and lower when exposed to 50000 myxospores $(0.1377 \pm 0.011 \mathrm{mg}$ ind. $\left.^{-1} \mathrm{~d}^{-1}, t_{4}=4.95, \mathrm{p}=0.0078\right)$. Adult growth of Great Lakes T. tubifex did not differ between the 0 and the 50000 myxospore treatments $\left(t_{4}=1.24, \mathrm{p}=0.2817\right)$; however, Great Lakes T. tubifex produced greater progeny biomass when exposed to 0 myxospores $\left(0.2057 \pm 0.014 \mathrm{mg}\right.$ ind..$\left.^{-1} \mathrm{~d}^{-1}\right)$ than when exposed to 50000 myxospores $\left(0.1189 \pm 0.006 \mathrm{mg}\right.$ ind. $.^{-1} \mathrm{~d}^{-1}, t_{4}=$ 5.43, $\mathrm{p}=0.0056)$.

A total of 239 progeny were assayed from oligochaete combinations containing Mt. Whitney and Great Lakes Tubifex tubifex. These assays revealed that 2 individuals from the same replicate shared bands characteristic of both Mt. Whitney and Great Lakes T. tubifex when using Primer 2 (Fig. 2A), indicating that hybrid progeny between the 2 strains were produced. Using the other 2 primers, the banding patterns of these 2 individuals displayed bands characteristic of Great Lakes T. tubifex only (Fig. 2B,C). Both strains of T. tubifex produced similar numbers of progeny regardless of the oligochaete combination.

The RAPD assay revealed that all individuals releasing TAMs in the $50 \mathrm{Mt}$. Whitney + 50 Great Lakes Tubifex tubifex treatments were Mt. Whitney T. tubifex. Total TAMs released $\mathrm{d}^{-1}$ (Table 2, ANOVA $F_{2,3}=$ 1.08, $\mathrm{p}=0.3795)$, TAMs released ind.$^{-1} \mathrm{~d}^{-1}$ (Table 2, ANOVA $F_{2,3}=0.55, \mathrm{p}=0.5968$ ) and prevalence of infected Mt. Whitney T. tubifex (Table 2, ANOVA $F_{2,3}$ $=1.01, \mathrm{p}=0.4621$ ) did not vary with oligochaete combination. No TAMs were found in any of the control treatments.

\section{DISCUSSION}

Both strains of Tubifex tubifex exhibited densitydependent intra-strain interactions consistent with previous studies (Kosiorek 1974, Bonacina et al. 1989). Mt. Whitney and Great Lakes T. tubifex exhibited strong intra-strain effects, indicated by a decrease in total biomass and progeny biomass production as initial density increased. We detected no difference in adult growth of either T. tubifex strain between density treatments. Thus, the intra-strain density-dependent effect on total biomass resulted from a reduction in reproduction. 


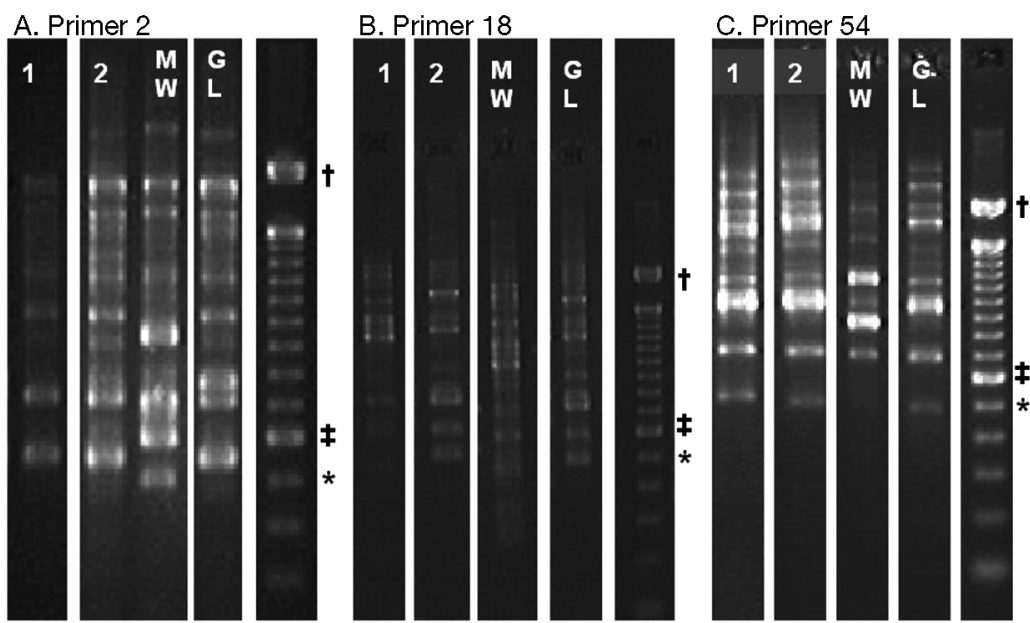

Fig. 2. Tubifex tubifex exposed to Myxobolus cerebralis. Randomly amplified polymorphic DNA banding patterns of $T$. tubifex progeny from a replicate exposed to myxospores and comprising both Mt. Whitney and Great Lakes individuals, showing PCR amplification products generated by 3 primers - 1 and 2: progeny DNA; MW: a known Mt. Whitney T. tubifex; GL: a known Great Lakes T. tubifex. (A) Primer 2 (5'-CCT GGG CTT G'-3'); (B) Primer 18 (5'-GGG CCG TTT A'-3'); (C) Primer 54 (5'-GTC CCA GAG C'-3'). Lanes on extreme right of each image shows GIBCO BRL $100 \mathrm{bp}$ DNA ladder (†: $2072 \mathrm{bp}$, ‡: $600 \mathrm{bp} ;$ *: $500 \mathrm{bp}$ ). Lanes 1 and 2 in (A) contain banding patterns consistent with hybrid progeny of Mt. Whitney and Great Lakes T. tubifex

Table 2. Tubifex tubifex exposed to Mxyobolus cerebralis. Total triactinomyxons released $\mathrm{d}^{-1}$, infection prevalence $(\%)$ and triactinomyxons released infected ind. $^{-1} \mathrm{~d}^{-1}$ (means $\pm 1 \mathrm{SE}$ ). In the $50 \mathrm{Mt}$. Whitney +50 Great Lakes treatment, triactinomyxon release and infection prevalence were calculated based on only the 50 susceptible T. tubifex (Mt. Whitney) that released triactinomyxons. Great Lakes T. tubifex did not release triactinomyxons

\begin{tabular}{|lccc|}
\hline $\begin{array}{l}\text { Oligochaete } \\
\text { combination }\end{array}$ & $\begin{array}{c}\text { Total TAMs } \\
\left(\mathrm{d}^{-1}\right)\end{array}$ & $\begin{array}{c}\text { Infection } \\
(\%)\end{array}$ & $\begin{array}{c}\text { TAMs released } \\
\text { ind }^{-1} \mathrm{~d}^{-1}\end{array}$ \\
\hline $\begin{array}{l}\text { 50 Mt. Whitney } \\
\text { Tubifex tubifex }\end{array}$ & $17586.73 \pm 4536.66$ & $41.0 \pm 10.0$ & $819.79 \pm 148.59$ \\
$\begin{array}{l}100 \text { Mt. Whitney } \\
\text { Tubifex tubifex }\end{array}$ & $16261.41 \pm 3180.77$ & $26.0 \pm 7.0$ & $637.07 \pm 121.21$ \\
50 Mt. Whitney + & $10935.34 \pm 1921.5$ & $31.0 \pm 4.0$ & $682.77 \pm 113.18$ \\
50 Great Lakes & & & \\
\hline
\end{tabular}

Inter-strain interactions between Mt. Whitney and Great Lakes Tubifex tubifex were similar to intra-strain interactions. The total and progeny biomass produced by an individual Mt. Whitney T. tubifex was lowest in treatments of $100 \mathrm{Mt}$. Whitney T. tubifex and $50 \mathrm{Mt}$. Whitney +50 Great Lakes T. tubifex. Similarly, total and progeny biomass produced by an individual Great Lakes T. tubifex were lowest in treatments of 100 Great Lakes and 50 Mt. Whitney + 50 Great Lakes T. tubifex. Adult growth was similar for all treatments and was unaffected by the addition of Great Lakes or Mt. Whitney individuals. This suggests that the inter-strain density-dependent effects on total biomass occurred because reproduction, but not adult growth, was depressed.

Adult growth of Tubifex tubifex was the only biomass variable that differed between myxospore doses of 0 and 2500. Interestingly, exposed adults of both strains exhibited greater growth than unexposed adults. These results were contrary to those of a previous experiment in which the total biomass of oligochaetes produced by $100 \mathrm{~T}$. tubifex exposed to 5000 myxospores was much lower than that of unexposed controls (Stevens et al. 2001). Key differences between our study and that of Stevens et al. (2001) may have contributed to the difference in results. First, Stevens et al. (2001) exposed oligochaetes to myxospores for the duration of their experiment. An extended exposure period to myxospores could have allowed oligochaetes to continue to ingest myxospores, thus having a continuing negative effect on their biomass. Second, Stevens et al. (2001) reported their results as the total biomass of adults and progeny of each treatment at the beginning and end of the experiment, which does not separate adult growth from the progeny produced.

An explanation for the higher growth of exposed adults at this particular dose may be parasite manipulation by Myxobolus cerebralis. By allocating more energy to growth, individuals may have been manipulated to have a larger gut capacity and hence greater TAM production potential. Although progeny biomass production did not differ statistically among myxospore doses, there was a trend of decreasing progeny biomass production as myxospore dose increased, suggesting that fewer resources may be allocated to reproductive output due to parasite manipulation. Host manipulations by parasites to increase parasite success have been detected in numerous host-parasite interactions (Moore 1984, Poulin 1994, Thompson \& Kavaliers 1994), and include altering host growth to benefit parasite production (Théron et al. 1992). 
The response of Great Lakes Tubifex tubifex to extremely high doses of myxospores revealed that total and progeny biomass were higher at a dose of 0 myxospores than at a dose of 50000 myxospores. Stevens et al. (2001) found similar results for 2 strains of T. tubifex that released TAMs at this myxospore dose. Adult growth was not affected by myxospore dose, contrary to the results comparing adult growth between 0 and 2500 myxospore doses. These results suggest that Great Lakes T. tubifex experiences a fitness cost when exposed to high, but not low doses of myxospores, and that this cost may be similar for susceptible strains exposed to similar doses of myxospores (Stevens et al. 2001). This cost could be the result of a debilitating byproduct of infection or a damage-limitation strategy. Fecundity reduction as a by-product of infection can result from host-impaired feeding or direct competition between host and parasite for host nutrients (Hurd 2001). Further, damage-limitation strategies, such as immune response to tissue damage, can direct resources into tissue repair, thereby reducing host fecundity (Hurd 2001). The reduced reproductive output of resistant $T$. tubifex was consistent with other reported host responses to parasitism, and may represent the cost of increased immunity (Minchella 1985, Bayne 1991, Forbes 1993, Sheldon \& Verhulst 1996, Stevens et al. 2001).

We did not detect statistically significant differences in parasite release and infection prevalence among oligochaete combinations, suggesting that neither oligochaete density nor the presence of resistant Great Lakes Tubifex tubifex affected the success of Myxobolus cerebralis within Mt. Whitney individuals. However, these results should be interpreted with caution for 2 reasons. First, the trend was for the prevalence of infection to decrease as the abundance of $T$. tubifex increased. Second, there were fewer TAMs released within the $50 \mathrm{Mt}$. Whitney +50 Great Lakes treatment than other treatments, even though the result was not statistically significant. Further comparisons of total TAM release among oligochaete combinations are warranted. Using a range of myxospore doses (including higher doses) and more replicates per treatment may help clarify these relationships.

Host response to a parasite may be characterized in several ways. A compatible host is one in which the parasite develops and an ensuing cost to the host is incurred, whereas for incompatible hosts, parasites do not develop, so there is no cost to the host (Vandame et al. 2000). Compatible hosts have varying degrees of susceptibility with varying levels of parasite development. Resistance by a compatible host prevents parasite development and typically involves an additional cost to the host (Vandame et al. 2000).
Our results suggest both Tubifex tubifex strains that we tested are compatible with Myxobolus cerebralis. Mt. Whitney T. tubifex are susceptible to infection; however, it is not clear if Great Lakes T. tubifex are less susceptible or resistant to infection because both responses incur a cost to the host.

Host susceptibility varies widely in other hostparasite interactions (Nayar et al. 1992, Ebert et al. 1998, Vandame et al. 2000) and is often coupled with parasite evolution (Ewald 1983, Minchella \& Scott 1991). Additionally, parasites may be capable of influencing the evolution of genetic variation for resistance among hosts (Ebert et al. 1998), leading to geographic patterns of adaptation whereby parasites are most virulent within local host populations and less virulent in novel hosts (Ebert 1994). This suggests that Tubifex tubifex strains with high susceptibility may have evolved with Myxobolus cerebralis, whereas resistant or less susceptible individuals are the novel host. The occurrence of $M$. cerebralis in North America is recent, first documented in 1956 (Hedrick et al. 1998). Because M. cerebralis shows minimal genetic variation among isolates (Andree et al. 1999, Whipps et al. 2004), there is little evidence that co-evolution has occurred. Examining the local adaptation of $M$. cerebralis and $T$. tubifex strains will determine the occurrence of such coevolutionary relationships.

The discovery of progeny that shared bands characteristic of both resistant and susceptible strains of Tubifex tubifex suggests that gene flow among T. tubifex strains occurs, at least in the laboratory. However, if the resulting progeny are rare in nature due to isolation or reinforcement (Freeman \& Herron 2001), then speciation among T. tubifex strains may be occurring. Possible prezygotic or postzygotic isolation of T. tubifex 'hybrids' and their reproductive success must be determined to predict gene flow among strains. If $T$. tubifex 'hybrids' survive and reproduce successfully, then their ability to propagate Myxobolus cerebralis must be determined to predict any effects upon host-parasite interactions.

We have shown that intra-strain and inter-strain interactions between Tubifex tubifex were densitydependent. We had expected that susceptible T. tubifex would be disadvantaged in competition with resistant individuals, and that resistant T. tubifex would reduce the infection prevalence among susceptible individuals. We detected neither effect in this experiment, although these hypotheses warrant further investigation. In addition, our results suggest that the Great Lakes T. tubifex is compatible with the parasite because high doses of myxospores impaired the reproduction of this strain even though they released no triactinomyxons. Consequently, in natural aquatic communities, resistant strains of $T$. tubifex may not reduce 
the effects of Myxobolus cerebralis on the salmonid host, particularly if sufficient numbers of susceptible T. tubifex are present.

Acknowledgements. We thank the Whirling Disease Initiative of the National Partnership for Native and Cold Water Fisheries for funds granted to B.L.K. Much gratitude to C. Fraser at the Wild Trout Research Laboratory, J. Zickovich Horn, K. Kinnan and the Western Fisheries Research Center for laboratory support, and C. Cada for editorial comments.

\section{LITERATURE CITED}

Andree KB, El-Matbouli M, Hoffmann RW, Hedrick RP (1999) Comparison of $18 \mathrm{~S}$ and ITS-1 rDNA sequences of selected geographic isolates of Myxobolus cerebralis. Int J Parasitol 29:771-775

Anlauf A (1994) Some characteristics of genetic variants of Tubifex tubifex (Müller, 1974) (Oligochaetea: Tubificidae) in laboratory cultures. Hydrobiologia 278:1-6

Anlauf A (1997) Enzyme variability of Tubifex tubifex (Müller) (Oligochaeta, Tubificidae) and seven other tubificid species. Arch Hydrobiol 139:83-100

Bayne CJ (1991) Invertebrate host immune mechanisms and parasite escapes. In: Toft CA, Aeschlimann A, Bolis L (eds) Parasite-host associations. Coexistence or conflict? Oxford University Press, Oxford, p 229-315

Beauchamp KA, Kathman RD, McDowell TS, Hedrick RP (2001) Molecular phylogeny of tubificid oligochaetes with special emphasis on Tubifex tubifex (Tubificidae). Mol Phylogenet Evol 19:216-224

Beauchamp KA, Gay M, Kelley GO, El-Matbouli M, Kathman RD, Nehring RB, Hedrick RP (2002) Prevalence and susceptibility of infection to Myxobolus cerebralis, and genetic differences among populations of Tubifex tubifex. Dis Aquat Org 51:113-121

Bonacina C, Bonomi G, Monti C (1989) Density-dependent processes in cohorts of Tubifex tubifex, with special emphasis on the control of fecundity. Hydrobiologia 180: 135-141

Brinkhurst RO, Jamieson BGM (1971) Aquatic Oligochaeta of the world. University of Toronto Press, Toronto

Chapman PM, Farrell MA, Brinkhurst RO (1982) Relative tolerances of selected aquatic oligochaetes to combinations of pollutants and environmental factors. Aquat Toxicol 2: $69-78$

Ebert D (1994) Virulence and local adaptation of a horizontally transmitted parasite. Science 265:1084-1086

Ebert D, Zschokke-Rohringer CD, Carius HJ (1998) Withinand between-population variation for resistance of Daphnia magna to the bacterial endoparasite Pasteuria ramosa. Proc R Soc Lond B 265:2127-2134

El-Matbouli M, Hoffmann R (1989) Experimental transmission of two Myxobolus spp. developing bisporogeny via tubificid worms. Parasitol Res 75:461-464

El-Matbouli M, Fisher-Scherl T, Hoffmann RW (1992) Present knowledge on the life cycle, taxonomy, pathology and therapy of some Myxosporea spp. important for freshwater fish. Annu Rev Fish Dis 3:367-402

El-Matbouli M, Gay M, McDowell TS, Georgiadis MP, Hedrick RP (1999a) The potential for using biological control technologies in the management of whirling disease. In: Proceedings of the Whirling Disease Symposium. Whirling Disease Foundation, Bozeman, MT, p 191-195
El-Matbouli M, McDowell TS, Antonio DB, Andree KB, Hedrick RP (1999b) Effect of water temperature on the development, release and survival of the triactinomyxon stage of Myxobolus cerebralis in its oligochaete host. Int J Parasitol 29:627-641

Erséus C, Prestegaard T, Källersjö M (2000) Phylogenetic analysis of Tubificidae (Annelida, Clitellata) based on $18 \mathrm{~S}$ rDNA sequences. Mol Phylogenet Evol 15:381-389

Ewald PW (1983) Host-parasite relations, vectors, and the evolution of disease severity. Annu Rev Ecol Syst 14: 465-485

Forbes MRL (1993) Parasitism and host reproductive output. Oikos 67:444-450

Freeman S, Herron JC (2001) Evolutionary analysis, 2nd edn Prentice-Hall, Upper Saddle River, NJ

Goldberg DE, Scheiner SM (2001) ANOVA and ANCOVAfield competition experiments. In: Scheiner SM, Gurevitch $\mathrm{J}$ (eds) Design and analysis of ecological experiments, 2nd edn. Oxford University Press, Oxford, p 77-98

Granath WO Jr, Gilbert MA (2002) Review: the role of Tubifex tubifex (Annelida: Oligochaeta: Tubificidae) in the transmission of Myxobolus cerebralis (Myxozoa: Myxosporea: Myxobolidae) In: Bartholomew JL, Wilson JC (eds) Whirling disease: reviews and current topics. American Fisheries Society Symposium No. 29. American Fisheries Society, Bethesda, MD, p 79-85

Grosholz ED (1992) Interactions of intraspecific, interspecific and apparent competition with host-pathogen population dynamics. Ecology 73:507-514

Hedrick RP, El-Matbouli M, Adkinson MA, MacConnell E (1998) Whirling disease: re-emergence among wild trout. Immunol Rev 166:365-376

Hurd H (2001) Host fecundity reduction: a strategy for damage limitation? Trends Parasitol 17:363-368

Kerans BL, Rasmussen C, Stevens R, Colwell AEL, Winton JR (2004) Differential propagation of the metazoan parasite Myxobolus cerebralis by Limnodrilus hoffmeisteri, Ilyodrilus templetoni, and genetically distinct strains of Tubifex tubifex. J Parasitol 90:1366-1373

Kosiorek D (1974) Development cycle of Tubifex tubifex Müll. in experimental culture. Pol Arch Hydrobiol 21:411-422

Lazim MN, Learner MA (1986) The life cycle and productivity of Tubifex tubifex (Oligochaeta: Tubificidae) in the moatfeeder stream, Cardiff, South Wales. Holarct Ecol 9:185-192

Markiw ME, Wolf K (1983) Myxosoma cerebralis (Myxozoa: Myxosporea), etiological agent of salmonids whirling disease requires tubificid worm (Annelida: Oligochaeta) in its life cycle. J Protozool 30:561-564

Milbrink G (1983) An improved environmental index based on the relative abundance of oligochaete species. Hydrobiologia 102:89-97

Minchella DJ (1985) Host life-history variation in response to parasitism. Parasitology 90:205-216

Minchella DJ, Scott ME (1991) Parasitism: a cryptic determinant of animal community structure. Trends Ecol Evol 6: $250-254$

Modin J (1998) Whirling disease in California: a review of its history, distribution, and impacts, 1965-1997. J Aquat Anim Health 10:132-142

Moore J (1984) Altered behavioural responses in intermediate hosts: an acanthocephalan parasite strategy. Am Nat 123:572-577

Nayar JK, Knight JW, Kaiser PE, Seawright JA, Narang SK (1992) Comparative susceptibility of species A, B and C of Anopheles quadrimacultus complex to infection with subperiodic Brugia malayi and Brugia pahangi (Nematoda: Filarioidea). J Am Mosq Control Assoc 8:61-64 
O'Grodnick J (1975) Whirling disease concentration using the continuous plankton centrifuge. J Wildl Dis 11:54-57

Park T (1948) Experimental studies of interspecies competition. I. Competition between populations of the flour beetles, Tribolium confusum Duval and Tribolium castaneum. Herbst-Ecol Monogr 18:265-308

Poddubnaya T (1980) Life cycle of mass species of Tubificidae. In: Brinkhurst RO, Cook DG (eds) Aquatic oligochaete biology. Plenum Press, New York, p 175-202

Poulin R (1994) The evolution of parasite manipulation of host behaviour: a theoretical analysis. Parasitology 109 (Suppl) S109-S118

Price PW, Westoby M, Rice B (1988) Parasite-mediated competition: some predictions and tests. Am Nat 131:544-555

Reynoldson TB, Rodriguez P, Madrid MM (1996) A comparison of reproduction, growth, and acute toxicity in two populations of Tubifex tubifex (Müller 1974) from the North American Great Lakes and Northern Spain. Hydrobiologia 334:199-206

SAS Institute (2001) SAS/STAT for Windows Version 8.1. SAS Institute, Cary, NC

Schall JJ (1992) Parasite mediated competition in Anolis lizard. Oecologia 92:58-64

Settle WH, Wilson LT (1990) Invasion by the variegated leafhopper and biotic interactions: parasitism, competition and apparent competition. Ecology 71:1461-1470

Sheldon BC, Verhulst S (1996) Ecological immunity: costly parasite defences and trade-offs in evolutionary ecology. Trends Ecol Evol 11:317-321

Steinbach LC (2003) Interactions among oligochaetes and a myxozoan parasite, Myxobolus cerebralis. Master's thesis, Montana State University, Bozeman, MT

Stevens R, Kerans BL, Lemmon JC, Rasmussen C (2001) The effects of Myxobolus cerebralis myxospore dose on tri-

Editorial responsibility: Albert Sparks, Seattle, Washington, USA actinomyxon production and biology of Tubifex tubifex from two geographic regions. Parasitology 87:315-321

Sturmbauer C, Opadiya GB, Niederstätter H, Riedman A (1999) Mitochondrial DNA reveals cryptic oligochaete species differing in cadmium resistance. Mol Biol Evol 16: 967-974

Subbarao SK, Vasntha K, Raghvendra K, Sharma VP, Sharma GK (1988) Anopheles culicifacies: sibling species composition and its relationship to malaria incidents. J Am Mosq Control Assoc 4:29-33

Théron A, Gérard C, Moné H (1992) Early enhanced growth of the digestive gland of Biomphalaria glabrata infected with Schistosoma mansoni: side effect or parasite manipulation? Parasitol Res 78:445-450

Thompson SN, Kavaliers M (1994) Physiological bases for parasite-induced alterations of host behaviour. Parasitology 109(Suppl): S119-S138

Vandame R, Colin ME, Morand S, Otero-Colina G (2000) Levels of compatibility in a new host-parasite association: Apis mellifera/Varroa jacobsoni. Can J Zool 78:2037-2044

Whipps CM, El-Matbouli M, Hedrick RP, Blazer V, Kent ML (2004) Myxobolus cerebralis internal transcribed spacer 1 (ITS-1) sequences support recent spread of the parasite to North America and within Europe. Dis Aquat Org 60: 105-108

Wolf K, Markiw ME (1984) Biology contravenes taxonomy in the Myxozoa: new discoveries show alternation of invertebrate and vertebrate hosts. Science 225:365-368

Yan G (1996) Parasite-mediated competition: a model of directly transmitted macroparasites. Am Nat 148: 1089-1112

Yan G, Stevens L, Goodnight CJ, Schall JJ (1998) Effects of a tapeworm parasite on the competition of tribolium beetles. Ecology 79:1093-1103

Submitted: January 8, 2005; Accepted: August 17, 2005 Proofs received from author(s): January 10, 2006 